considerable strain on the left side of the vessel, and it was here probably that the rent commenced.

The specimen is preserved in the museum at Sydenham College, Birmingham.

\section{REMARKS ON SYPHILISATION.}

By Grorar Gaskorn, Esq., Surgeon, Chevalier of the Order of Christ, Portugal; Surgeon to the Artists' Benevolent Fund; formerly House-Surgeon and House-Pupil, St. George's Hospital.

$$
\text { [Continued from p. } 518 \text { of vol. i for 1866.] }
$$

Is our last we had to consider that argument of Henry Lee, in which he rests his point wholly on the character of induration in the chancre, which is better described by Ricord as characteristic and complementary, not as a feature essential to the course of infection. We are surprised that a man who makes pretensions to philosophy should fix on a single sign or character as bringing about results which occur commonly enough without its presence or precedence; and this is what Mr. Lee does when he makes this induration a "potential" as well as an "essential" sign of syphilitic infection. The temptation which physicians are under to mistake effects for causes, is favoured by our habit of clinical study, which directs itself exclusively to the manifestations of the disease, apart from the consideration of cause; the natural bias of our minds leading us ever to contemplate one or more prominent symptoms as governing the rest; especially when priority in order of sequence gives a plea for power. But what need we seek for more in the present case than the virus, as a complete and sufficient cause for all the phenomena? The thing itself is well enough understood by its effects. We need not be squeamish about Inaming it, like some pseudo-philosophers who would narrow the field of human thought till a man believed in nothing but the food between his teeth. We say fearlessly, then, that there is no stronger proof of the existence of a thing than the multiplied and long evidence we have of its action or of its being acted on; and in this we believe not to err against the laws of ancient or modern thought; and that is the case in the instance before us; and where the cause is one, its manifestations will vary according to the inconstant conditions of the matter subject to its operation.

As to this contagion of syphilis, we know of it by its persistency and generative power; and we cannot but recognise its modifications no less than its integrity. There is syphilitic matter which is like a searing iron in its action on the tissues; and sometimes we have ulceration and loss of tissue in its mildest forms; not seldom there is an excessive destruction and shedding of cell-formations which escape in the form of pus; and perhaps such celldeath is not, then, the single and exclusive effect of the virus on the economy. At other times, there is matter which enters the human frame with scarce a blot or stain of discoloration on the surface, yet it taints the blood and torments the body for years; and there is also that well recognised form, occurring chiefly in the male sex, which is capped by induration, such as is described by Mr. Lee. All these are primary manifestations; and the same may be said of those which are secondary-that induration, of whatever kind, is not a necessary complication in them.

But, if generally in the course and train of contagion like produces like-just as mumps from malaria produces mumps by contagion, and not an intermittent fever-we are not driven on that account to accept duality or a plurality of causes. We take into consideration that both the virus and its field of operation vary much; and especially do we hesitate when we see that the very men who dogmatise upon this subject, and offer us the conclusions of their narrow experience in a path confessedly difficult, shun and avoid a wider arena of experiment which is thrown open to them, and would fain bar and lock the doors. When a man has practised syphilisation, he may be allowed to have an opinion of his own on these questions, and may be excused from accepting theories which are no longer reconcileable with his everyday experience. And when Daniellsen, the Norwegian professor, says that he has seen thousands of artificial ulcers, and that (with one exception) they were all chancroids, we know that he means no more but that they were all of them non-indurated sores; and, being such, he concludes that they can in no way affect the system, or, at least, ought not to affect it. We understand that very well. "The long established axiom" of M. Clerc, that the chancroid does not infect, holds him fast; and he has bent his mind to these established axioms. In five lepers on whom he inoculated from the soft chancre, he did not get the result he thought himself entitled to expect, according to his interpretation of unity; viz., secondary syphilis ; and because he did not get these particular forms of disturbed function, therefore he falls in, it would seem, with the extreme opinion, that the direct operation of such chancres is exclusively local and limited to the spot on which they grow; if neither one, nor two, nor three, nor thirty-six, nor a hundred and thirty-six, induce secondary syphilis, then he feels justified in asserting that no number will do so. Failing the manifestations of secondary syphilis on the subjects of experiment, he negatives the possibility of all or any other influence upon the frame whatever as impossible, and in this he does not, as it would seem to us, betray the philosopher; but, in preferring the "long established axiom", he brings the professor into view.*

Much has been said of his sixth case, where, after 287 inoculations on a leper made with the secretion of soft sores, accidental inoculation from an indurated sore produced a hard chancre, after which constitutional syphilis ensued; showing that, at the time this happened, no immunity was acquired. Now, although immunity commonly follows at the end of 350 inoculations or so, yet the range is wide and uncertain; and in this case the patient had not reached that point of immunity, and what followed from inoculation of the hard chancre was a matter of course.

Boeck, on the other hand, syphilised a woman who had obstinate chronic eczema; and, even as late as five years after, on repeated trials, she could not be inoculated from the hard chancre, nor were there any secondaries in her case. Since that time, or thereabouts, Boeck has inoculated only with the secretion of the hard chancre and its product in direct linear series. This is a saying hard to be borne by those who blindly follow the dictamina of Messrs. Ricord, Fournier, and Rollet; and then it becomes a question what liberty we are allowed in departing from their ideas in England and in Norway, and what amount of "initiative" is forbidden in Europe by these "French swells", who think all linen dirty that is not washed in French waters.

In producing immunity, it is necessary not to stop

* We are far from judging that this criticism applies with correctness to the opinions of M. Daniellsen; it is only meant for the interpretation or misinterpretation of them given in our manuals. (See Bumstead On Syphilis.) 
half way in syphilisation; but to let the patient, so to speak, have the sword up to the hilt. There is a near limit which Nature has with certainty assigned to the inoculation of chancres, and which cannot be overpassed. If immunity have been produced by the soft sore, we look upon it as impossible that a hard chancre and secondaries can be communicated. What is very certain is that, when immunity is produced through the medium of the secretion from the hard sore, the inoculation of that biting pus from the soft sore has, when inoculated, no more effect than a drop of water on the skin. Let the dualists explain this, and they will hereafter find more to explain.

The opinion has been circulated, and industriously maintained, that, when syphilisation was first introduced and Dr. Boeck adopted these ideas, the world was yet in darkness as to the distinction between the two kinds of sores, and as to the subsequent infection of the individual more or less in correspondence to their anatomical character; the egg of this discovery is supposed to have been hatched in the years 1852-54. This is not the case; for practically the thing was well understood, as now, by Ricord and Auzias-Turenne, as men of the time (not to speak of the light afforded by older sources of study), though not pushed to the extreme of dogma, as has occurred since; for those young men, Bassereau and Clerc, whose works are referred to, only worked out with industry ideas which they picked up in the schools of Paris. To show that this was the case, we need only quote the language of the noble Malgaigne, in his fruitless defence of syphilisation, in the debate at the Academy, August 10th, 1852. He says: "All the best discoveries of $M$. Ricord drove us forward in this direction. First, there is that capital distinction between the simple chancre which does not give the pox and the indurated chancre which gives it with fatality - a fact which seems to constitute this chancre as the real syphilitic sore. Next, have we not received as doctrine, that a bubo secreting specific pus preserves the patient from constitutional syphilis? And thirdly, we have the law that syphilis only attacks the constitution once; out of which observation Ricord drew the inference that a man once refractory to the virus might convey the immunity to his offspring. How was it possible, where Nature has displayed so many paths of escape from a terrible malady, not to hope that art might go hand in hand with her at some not distant time? Thus you see, gentlemen, syphilisation came quite naturally out of this school of ours." And then he mentions that Castelnau and Parent-Duchâtelet had observed immunity against the chancre in certain individuals; and that Ricord had, time without end, not only prophesied that syphilis would find its vaccine, but had till then ever spread his sail in that direction.

Henry Lee says that no evidence has ever been adduced to show that any animal was ever inoculated from an infecting sore. Certainly, yes; there is such a thing as evidence, and there are also laws of evidence which exist for all mankind. Mr. Lee appeals to evidence, when it would have been fitter for his purpose to have kept its very existence out of sight. He has indeed so long asserted the proposition before us, that he must believe it strongly; yet has he no argument on his side but what is founded on the alleged incompetence of men like AuziasTurenne, Malgaigne, Langlebert, and Cazenave, in Paris, and, in Vienna, the celebrated Sigmund. In truth, as regards syphilisation, evidence has been strangled in its birth, and the laws of evidence have been thrown to the winds, in the eagerness of its opponents to keep it out of the field, for fear of interference with their views. The common sense which finds place in all besides, is put to the ban and wholly disallowed when syphilisation is in question. In no other argument has such enormous capital been made out of the prejudices of the vulgar. So far from no evidence having been adduced, it is a notorious fact, that this point of the communicability of syphilis to animals, as tested by the presence of secondary symptoms, has been thoroughly entered upon, and passionately discussed, from the first time when these questions were in agitation. When, therefore, Mr. Lee says there was no evidence, he would seem to mean that, on the side of Anzias-Turenne, it was discussed without evidence of facts, and on purely theoretical grounds; and that all the evidence of facts was on the other side. The contrary was the case. The arguments against the communicability of syphilis to animals were negative and theoretical; those in proof of communicability were of a positive and demonstrable nature.

Whether the baboons of M. Auzias-Turenne and M. Langlebert, or the cats afflicted with exostosis brought forward by M. Malgaigne, or that interesting brood of kittens which were so much in print, had really secondary syphilis or not, need not occupy us now ; it is sufficient to say they were en evidence. M. Auzias-Turenne's calm reply to much passionate logic deserves to be quoted. "When one writes", he says, "with a cat upon one's knees having multiple exostosis and an abundant psoriasis, it is impossible to yield to such beautiful arguments." The whole question at issue was, Can syphilis, or, if you will, the right pox, be communicated to animals; can it be inoculated into brutes? All analogy is in favour of such communicability; and, we may fairly add, such a degree of belief as can be drawn from the laws of evidence, or, at the very least, of human testimony.

Was M. Auzias-Turenne an unslkilful experimenter or an uncandid exponent of his views? After passing through the fire of persecution, has he turned out to be the impostor and visionary that he was proclaimed to be by certain men in power, upholders of the status quo? On the contrary, has he not risen, have not they somewhat declined, in public esteem? We never heard anything against M. Auzias-Turenne, except that he showed that common foible of his countrymen of being a little too much a systemmaker. Let us look at the fifty-third proposition in his original communication to the Academy, delivered in the year 1850. "It is seldom that an ape is sub. jected to a succession of chancres without one or two of them becoming indurated; but when this induration has shown itself on one or two chancres, it does not occur in those which follow." It may be suggested that in those days the difference between the hard and soft sore was not appreciated; but familiarity with writings of the period will show that practically as regards their connection with secondaries the difference was as well understood as now. That all may not rest on one pain of shoulders, let us say that, as regards the occurrence of consecutive syphilis in animals, Sigmund of Vienna has confirmed all the conclusions of M. Auzias-Turenne; and, if $\mathbf{M r}$. Lee tell us that there is a gentleman in Lyons (M. Basset) who has tried to produce such a result and failed, we will tell him that there is a gentleman in Iondon who might have succeeded if he had tried it and had he been minded so to do-that is, supposing him to bring a fair amount of skilfulness to the task. It is a little too much to say of experiments conducted with painstaking and laborious industry that they are nought, when it would be suffcient to mention the names of their impugners to show that these gentlemen were of one school, specialists rather than surgeons, clumsy experimenters, and the general course of their doctrines not walking hand in 
hand with the truth. Such, indeed, denied not this point of the occurrence of secondaries alone, but they went on headlong, and at that time they denied everything. The inoculation on animals of the soft ehancre they no longer deny. And, if it were necessary to say more on the subject, we might mention the name of one who stands highly eminent in syphilography, who had inoculated himself on a delicate part of his person from a ctancre in a cat. Under a strong feeling of alarm, the ensuing chancre was removed by incision ; and when examined microscopically ad hoc by curious and competent observers, it was found to contain all those fibro-plastic and particular elements declared by Robin and others to characterise the indurated syphilitic sore.

[To be continued.]

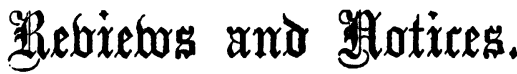

Defects of Sight and Hearing; their Nature, Causes, Prevention, and Management. By $T$. Wharton Jones, F.R.S., F.R.C.S., Professor of Ophthalmic Medicine and Surgery in University College, London; etc. Second Edition of Defects of Sight. Pp. 168. London : 1866.

Mr. Wharton Jones has revised the former edition of this little book, and has added some remarks on Defects of Hearing. The book appears intended for popular as much as, or rather more than, for professional use. For the latter purpose, indeed, it is not so valuable as several other well known treatises; but, while the author sometimes gives the public a little more information regarding treatment than is necessary for them to know, the book contains information which may be usefully and safely imparted.

ON THE Use OF THE SPhygmograph IN the INvestigation of Disease. By B. W. Foster,

M.D. Pp. 42. London : 1866.

OUR readers are already well acquainted with the contents of this little volume, which contains, in a separate form, the papers which have recently appeared in this Journal. For publishing them now Dr. Foster has been seriously called to account by one of our contemporaries. He has been told that he ought not to have published this pamphlet, because two other physicians, who have been much longer than he engaged in experimenting with the sphygmograph, were upon the point of publishing their researches in the Lancet; that his pamphlet is little more than a "collection of cuttings" from Marey's work ; and that he is unduly appropriating credit which belongs to others. To these accusations Dr. Foster gives a formal denial. That he never attempted to appropriate the credit of introducing the instrument into England is proved, he says, by the fact that, in his pamphlet, he thanks Dr. Anstie for " his first acquaintance" with it, and for having introduced it into this country. His answer to its being a "collection of cuttings" is, that "it contains an account of a few of the many experiments made by Dr. Foster in confirmation of the French authors; that it contains twenty-one engravings of pulse-traces taken by himself from cases of diseases, and selected from some two hundred observations made at the Qucen's Hospital"; that "every pulse-trace in the pamphlet is original"; and that "sentences translated from Marey's work are marked by inverted commas." Dr. Foster adds, that M. Marey, in a complimentary letter, asks permission to publish Dr. Foster's results. Dr. Foster adds that, when "the stethoscope, the ophthalmoscope, and the laryngoscope, were invented, he is not aware that any one claimed a monopoly in their application or in the discussion of their merits."

Photographs (COlodred From Life) of the Diseases of The Skuv. Second Series. By Alex. Balmanno Squire, M.B.Lond., Surgeon to the West London Dispensary for Diseases of the Skin ; Lecturer at St. Mary's Hospital Medical School. No. IIr. London: 1866.

The number before us of Mr. BalmanNo Squire's photographs of skin-diseases represents a case of Prurigo Senilis. In the letter-press which accompanies the plate, the author states that the views which he entertains regarding the disease vary from those of other writers on the subject. He holds that the essential cause of the disease is the Pediculus Corporis.

"This parasite is, however, not always easy to find. Its presence is often unsuspected by the patient, and when known to him is as often denied; hence, its invariable co-existence with this form of eruption has, until very recently, escaped the notice of observers. This constant relation of the parasite to the disease, as cause to effect, was first pointed out by the author in 1864."”

Prurigo senilis, Mr. Squire observes, is-as one would expect if its cause be universally such as he describes it-contagious. As its name denotes, it is most common in old persons; but is sometimes met with in the middle-aged, and even in children. Cachexia and debility are favourable to its production; but it is not absolutely confined to the poor and ill fed; for Mr. Squire refers to the case of a nobleman long since dead, who had the disease to the end of his life, and in whom the affection was associated with the presence of pediculi.

It is evident, that Mr. Squire has investigated with much care the very troublesome disease of which he has given a representation in the present number of his instructive series.

The Chemistry of Common Things. By Stevenson Macadam, Ph.D., F.R.S.E., F.C.S., Lecturer on Chemistry in the Medical School, Surgeons' Hall, and to the School of Arts, Edinburgh ; etc. Pp. 184. London : 1866.

THIs little treatise is intended for use in schools; and contains, in plain and simple language, an exposition of common facts in chemistry.

The arrangement followed by the author is the following : Chapter 1, The Chemistry of the World around us; 2, Constituents of the Atmosphere; 3, The Plant and what it feeds on ; 4 and 5, The Plant and what it yields us; 6 and 7, The Animal and what it feeds on ; 8, Importance of Saline Food; 9, The Saline Food of Plants and Animals; 10, The Decay of Plants and Animals; 11, The Circulation of Matter.

Dr. Macadam has not aimed at giving even an outline of the details of chemical notation and nomenclature, or chemical combination; but has 